\title{
THE LAUGHLEN TEST IN SYPHILIS
}

By ROBERT KEMP, M.D.(Liverp.); M.R.C.P.(Lond.); Research Assistant, Department of Medicine, Liverpool University. Director: Professor Henry Cohen.

THIs test seemed to offer an opportunity for the earlier diagnosis of late syphilis and particularly neuro-syphilis. A survey of a series of patients with neuro-syphilis in the Liverpool Royal Infirmary showed that the prognosis, even with most active therapy was very poor. This was mainly due to the fact that when the patient was brought to diagnosis as a result of the usual symptoms, too much damage had already been done to allow recovery; for good results the diagnosis should have been made at an asymptomatic stage. Clearly the only method of doing this would be to uncover the cases of latent infection by large-scale routine blood testing of the general population or at least of such sections of it as come under control, for example, hospital patients, panel patients, men in the services and so on.

But such a scheme presents three difficulties. Firstly, that the percentage of syphilitics in the general population in this country is low. For instance, the proportion of positive blood sera found in $8 \mathrm{I} 4$ of $\mathrm{I}, 587$ patients admitted to the Liverpool Royal Infirmary under Professor Henry Cohen was only $8 \cdot 4$ per cent., as shown in Table I., though

\section{Table I.-Serum W.R. in Hospital Patients.}

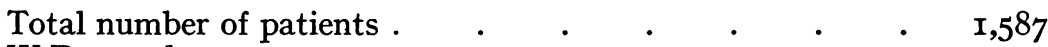

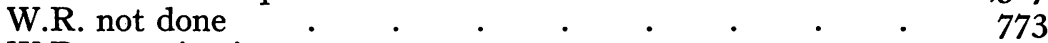

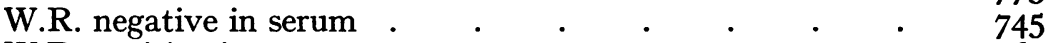

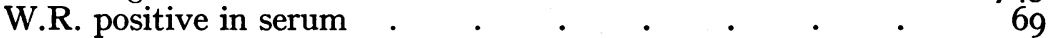

$\begin{array}{lllll}\text { Total tested } & \text {. } & \text { 814. } & \text { Percentage positive } & \mathbf{8 . 4}\end{array}$

the tested patients included a number with symptomatic neuro-syphilis ; it is significant, however that at least eleven unsuspected positives were discovered by the testing of these patients. The second difficulty is the time and expense of obtaining specimens for and carrying out 


\section{BRITISH JOURNAL OF VENEREAL DISEASES}

large numbers of negative Wassermann tests. The third is that in neuro-syphilis it is well known (and rather overemphasised) that the blood W.R. may be negative. The English experience as stated by the late Dr. James Collier is that though the serum W.R. at diagnosis may be negative in 30 per cent. of tabetics, it is positive in nearly Ioo per cent. of other types of neuro-syphilis. The figures in Table II., based on patients in the Liverpool Royal

\section{Table II.-The Serum W.R. IN Io9 Cases of NEURO-SYPHILIS}

\begin{tabular}{|c|c|c|c|c|}
\hline Diagnosis & & $\begin{array}{c}\text { Number of } \\
\text { Cases }\end{array}$ & $\begin{array}{l}\text { Number } \\
\text { Positive }\end{array}$ & $\begin{array}{c}\text { Percentage } \\
\text { Positive }\end{array}$ \\
\hline $\begin{array}{l}\text { Tabes Dorsalis } \\
\text { General Paresis } \\
\text { Meningo-vascular } \\
\text { Taboparesis . } \\
\text { Congenital . } \\
\text { Gumma Meninges } \\
\text { Other . . }\end{array}$ & $\begin{array}{ll}\cdot & \cdot \\
\cdot & \cdot \\
\cdot & \cdot \\
\cdot & \cdot \\
\cdot & \cdot \\
\cdot & \cdot \\
. & .\end{array}$ & $\begin{array}{r}43 \\
29 \\
22 \\
6 \\
6 \\
2 \\
1\end{array}$ & $\begin{array}{r}33 \\
26 \\
21 \\
5 \\
6 \\
2 \\
1\end{array}$ & $\begin{array}{l}77 \\
90 \\
95 \\
- \\
- \\
-\end{array}$ \\
\hline
\end{tabular}

Infirmary agree closely with this. It is essentially a matter of rapidity with which the neurological lesion develops. Cases of tabes would be found to have a positive serum W.R. by routine testing as frequently as would other types in, say, the first ten or fifteen years after infection.

What is wanted then for the detection of latent syphilis is a rapid, reliable serum test which can easily and cheaply be applied to large numbers of people. It should be more sensitive than the Wassermann, but need not be so specific since in such a scheme all positive reactors would be further tested by the W.R. and clinically examined. The Laughlen test promised to fulfil these requirements, and this investigation was planned with two objects :

(a) To determine the ease and accuracy of its technique and

(b) To compare its results with those of the W.R. and the clinical diagnosis. 


\section{THE LAUGHLEN TEST IN SYPHILIS}

\section{TECHNIQUe}

The reaction was developed logically from the Kahn test by Laughlen (I935) at Toronto. Kahn antigen is sensitised by cholesterol and emulsified by Friar's balsam. By adding a little fat soluble dye the large particles formed in a positive reaction pick up the dye and are stained red. The clearing of the emulsion and the red flocculation are easily seen with the naked eye. Two drops of the serum to be tested and the antigen are mixed on glass slides with the same simplicity as in blood grouping. The stronger the infection the more rapid the reaction; degrees of positivity are therefore determined by timing. It will be seen that the only apparatus required is a platinum loop and glass slides, and enough serum can be obtained by the collection of a little blood from an ear-prick. Sera can be tested at the rate of forty to fifty an hour, though it is of course advisable that each sample should be tested in duplicate.

Despite this apparent simplicity, a good deal of experience is necessary for accurate working. The making of the emulsion-though substantially that described by Laughlen-is an art. Our technical assistant, Mr. K. M. Wilson, A.I.C., prepared the material used here and will shortly publish a technical note. The reagent has then to be brought to the required sensitivity, by the fractional addition of electrolyte, and standardised against sera of known reaction. The sensitivity can be varied within wide limits so that standardisation is a major problem.

In addition to antigen prepared in our own laboratory, commercial antigen (Lederle) was also used. With this latter over six hundred sera were tested. It had the disadvantage of being prepared as a specific test for syphilis, and the resulting lack of sensitivity was shown in its producing many fewer positive reactions than our own antigen and the W.R. Even though the sensitisation stated by the manufacturers to be necessary was varied considerably, the test with this antigen remained more sluggish. The commercial antigen was therefore not good enough for use by occasional or inexperienced workers and had it been used exclusively for this series the results would have been poor.

Published reports on this test are still few. Laughlen (I938) has found a 99 per cent. agreement with the Wassermann reaction and a $99 \cdot 6$ per cent. one with the 


\section{BRITISH JOURNAL OF VENEREAL DISEASES}

Kahn in about 3,000 sera. Robinson and Stroud (I937) in about $\mathrm{I}, 000$ sera found a 93 per cent. agreement with the Wassermann and a 97 per cent. agreement with the Kahn. Price (I937) tested the Laughlen method against several other standard tests for syphilis in 257 sera and found it slightly more sensitive than the Kahn, and both flocculation tests were more sensitive than the Wassermann. An adverse report comes from Usher (I938) who in a small series of normal and syphilitic sera could not get the antigen to work properly. His work is open to several detailed criticisms, but it would appear mainly that his results are more an illustration of difficulties in technique than a criticism of the test.

\section{MATERIAL}

The sera used for this trial of the Laughlen test were very kindly provided by Professor Davie of the Thompson Yates laboratory, who allowed me to use all the sera sent to him after he had carried out the W.R. In this way I,I24 sera were tested in parallel. The W.R., the Laughlen reaction and clinical data were compared after the first 500 tests and at the end of the series. Prior to the comparison reported here a hundred sera were tested to establish the technique.

\section{RESULTS}

The results can be seen in Table III. Groups $a$ and $b$ show that there is agreement between the W.R. and the Laughlen test-both positive and negative-in 94.2 per

TABLE III.-RESUlts.

\begin{tabular}{c|l|l|l|r|r}
\hline Group & \multicolumn{1}{|c|}{ Clinical } & $\begin{array}{c}\text { Wassermann } \\
\text { Test }\end{array}$ & \multicolumn{1}{c|}{$\begin{array}{c}\text { Laugblen } \\
\text { Test }\end{array}$} & Number & Per Cent. \\
\cline { 2 - 5 } & Non-syphilitic & Negative & Negative & 945 & $84 \cdot 2$ \\
a & Syphilitic & Positive & Positive & II3 & I0・0 \\
b & Syphilitic & Positive & Negative & 9 & $0 \cdot 8$ \\
c & Syphilitic & Negative & Positive & 26 & \} \\
d & Non-syphilitic & Negative & Positive & 29 & $4 \cdot 9$ \\
\hline
\end{tabular}

Groups $a$ and $b$ contain some sera of which the clinical data are not known, but they are included here (for convenience) since the W.R. and Laughlen are in agreement. 


\section{THE LAUGHLEN TEST IN SYPHILIS}

cent. of cases. Groups d and e total another 4.9 per cent. showing the higher sensitivity of the Laughlen. But though in Group $\mathrm{d}$-all patients under treatment-the Laughlen was correct, in Group e it may have been nonspecific. This last group is not a matter for concern since to get the Laughlen test working properly it is probably essential to set it on the sensitive side. It is proposed in any scheme of routine testing to check all positive reactions by W.R. and clinical examination, and a false positive can therefore easily be eliminated. But Group c-again all patients who were under treatment-showed nine instances, or 0.8 per cent., in which apparently a false negative was given by the Laughlen test, but on analysis it was found that this group could have been practically eliminated by rigid technique and complete duplication and checking. Two of the sera were tested only with the commercial antigen, two only with a batch of our own antigen which was subsequently shown to have been inadequately sensitised. In others faint positives had not been re-checked. Even under treatment the Laughlen test should theoretically-since it is based on Kahn antigen-be more sensitive than the W.R. as indeed it proved in Group d.

\section{SUMMARY}

(I) The Laughlen test has been carried out in parallel with the Wassermann in I,IOO cases, and checked with the clinical condition in the majority of instances.

(2) There was agreement with the W.R. in $94^{\cdot 2}$ per cent. of sera.

(3) The W.R. was in agreement with the clinical condition in 97.6 per cent. of cases.

(4) The Laughlen was in similar agreement in $96 \cdot 6$ per cent. of cases.

(5) The test is not so specific as the Wassermann, especially when made as sensitive as possible, but with the proviso that positive reactions are to be used only as indications for further investigation, within reasonably close limits, its actual degree of non-specificity is not very important.

(6) Practical experience shows that the test is simple, rapid, cheap and accurate enough to be used for the large scale detection of latent syphilis. 
BRITISH JOURNAL OF VENEREAL DISEASES

\section{ACKNOWLEDGEMENTS}

This work was made possible by the kindness and help of Professor Davie. I am indebted to Lederle Laboratories for supplies of commercial antigen.

\section{BIBLIOGRAPHY}

Laughlen, G. F. (I935) Can. M.A.J., 33, I99.

Laughlen, G. F. (I938) Can. Pub. Health J., 29, 396.

Price, A. S. (I937) Med. Times, N.Y., 65, 396.

Robinson, F. H. and Stroud, G. M. (I937) J. Amer. Med. Ass., 108, II70.

Usher, G. S. (I938) Amer. J. Syph., Gonor. \& Ven. Dis., 22, $45^{2}$. 